\title{
Saponins from Leaves of Kalopanax septemlobus (THUNB.) KOIDZ.: Structures of Kalopanax-saponins
La, Lb and Lc
}

\author{
Chun-Jie ShaO, ${ }^{a}$ Ryoji KaSAI, ${ }^{b}$ Kazuhiro Ohtani,${ }^{b}$ Jing-Da XU, ${ }^{a}$ and Osamu TANAKA ${ }^{*, b}$ \\ Department of Chemistry, Bethune University of Medical Sciences, ${ }^{a}$ Xinmin Street 6, Changchun, China and.Institute of Pharmaceutical Sciences, \\ Hiroshima University School of Medicine, ${ }^{b}$ Kasumi, Minami-ku, Hiroshima 734, Japan. Received June 23, 1989
}

From leaves of Kalopanax septemlobus (THUNB.) KoIDZ., three new saponins named kalopanax-saponins La (6), $\mathrm{Lb}$ (7) and Lc (8) were isolated together with five known saponins, kalopanax-saponins $A$ and B, akeboside Stb, eleutheroside $K$ and saponin $P g$. The new sapogenin 9 named kalopanax-genin $L 1$, which is common to 6, 7 and 8 , was formulated as $22 \alpha$-hydroxyhederagenin. On the basis of chemical and spectral data, the structures of these saponins were elucidated as follows: $3-O-\alpha$-L-arabinopyranosyl-22 $\alpha$-hydroxyhederagenin $(6), 3-O-\alpha$-L-rhamnopyranosyl-(1 $\rightarrow 2)-\alpha-L-$

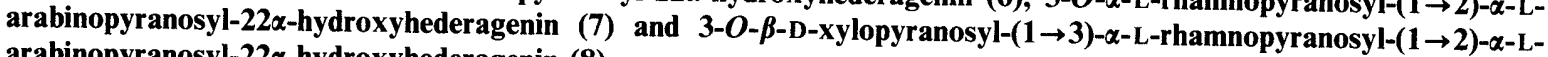
arabinopyranosyl-22 $\alpha$-hydroxyhederagenin (8).

Keywords Kalopanax septemlobus; Araliaceae; Chinese folk medicine; ciqiu; saponin; kalopanax-saponin; $22 \alpha$-hydroxyhederagenin; $3 \beta, 22 \alpha, 23$-trihydroxyolean-12-en-28-oic acid

In the previous paper, ${ }^{1)}$ we reported the isolation and structural determination of three new saponins named kalopanax-saponins $\mathrm{C}, \mathrm{D}$ and $\mathrm{F}^{2)}$ together with four known saponins from roots of Kalopanax septemlobus (THUNB.) KOIDZ (Chinese name: ciqiu 刺楸, Japanese name: harigiri) collected in Jilin district, North-East China. Continuing the investigation of this plant, we have studied saponins of the leaves of this plant. The present report deals with isolation and structure elucidation of three new saponins together with identification of five known saponins from the leaves.

Air-dried leaves of Kalopanax. septemlobus were extracted with methanol. A suspension of the methanolic extract in water were washed with ethyl ether and extracted with ethyl acetate and then with 1-butanol saturated with water, successively. The ethyl acetate extract was subjected to chromatography on silica gel followed by highperformance liquid chromatography (HPLC) to give saponins 1, 2, 3, 4, 6, 7 and 8 (yields from dried leaves: 0.008, $0.01,0.21,0.006,0.01,0.002$ and $0.04 \%$, respectively). Chromatography of the butanolic extract in a similar manner afforded a saponin 5 (yield from dried leaves:

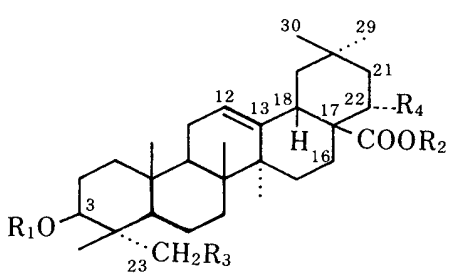

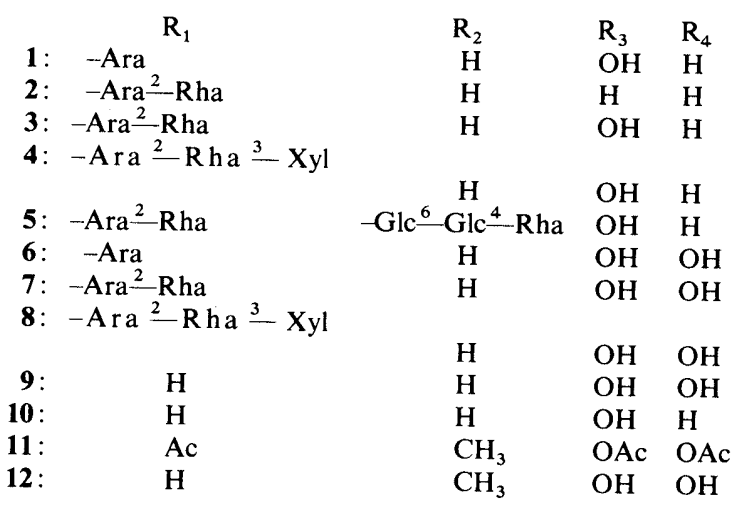

Chart 1
$0.05 \%$ ).

Based on the proton- and carbon-13 nuclear magnetic resonance $\left({ }^{1} \mathrm{H}\right.$ - and $\left.{ }^{13} \mathrm{C}-\mathrm{NMR}\right)$ evidence and the result of acid hydrolysis, as well as comparison of the optical rotations, saponin 1 was shown to be identical with akeboside Stb from Akebia quinata (= $\beta 2$-fatsin from Fatsia japonica) ${ }^{3)}$ In the same manner, saponin 2 was found to be identical with eleutheroside $\mathrm{K}$ from Acanthopanax senticosus $^{4}$ and saponins 3 and $\mathbf{5}$ were proved to be identical with kalopanax-saponins $A$ and $B{ }^{1.5)}$ respectively. Saponin 4 was identical with saponin $\mathrm{Pg}$ from Akebia quinata. ${ }^{6}$

A new saponin 6 named kalopanax-saponin La, on acid hydrolysis, afforded arabinose and a new sapogenin 9 named kalopanax-genin L1. The positive and negative fast atom bombardment mass spectrum (FAB-MS) of 9 exhibited $(\mathrm{M}+\mathrm{Na})^{+}$at $m / z 511(488+23)$ and $\left(\mathrm{M}-\mathrm{H}^{-}{ }^{-}\right.$at $m / z$ $487(488-1)$, respectively. The ${ }^{1} \mathrm{H}$ - and ${ }^{13} \mathrm{C}$-NMR spectra (in $\mathrm{C}_{5} \mathrm{D}_{5} \mathrm{~N}$ ) of 9 showed six quaternary methyl signals [proton signals at $\delta 0.93,0.94,1.10,1.11,1.12,1.14$ (each
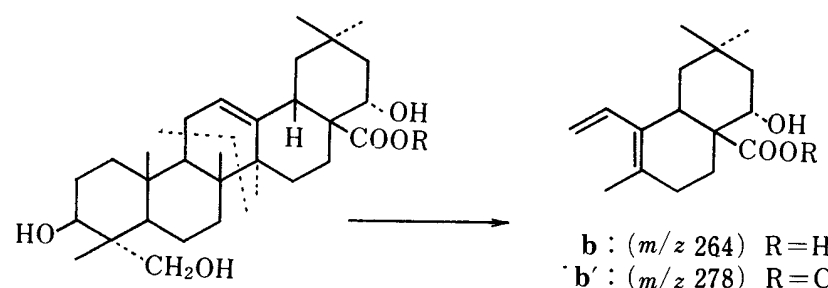

$$
\text { b : }(m / z 264) \quad \mathrm{R}=\mathrm{H}
$$$$
\mathbf{b}^{\prime}:(m / z 278) \mathrm{R}=\mathrm{CH}_{3}
$$

9: $\mathrm{R}=\mathrm{H}$

$12: \mathrm{R}=\mathrm{CH}_{3}$
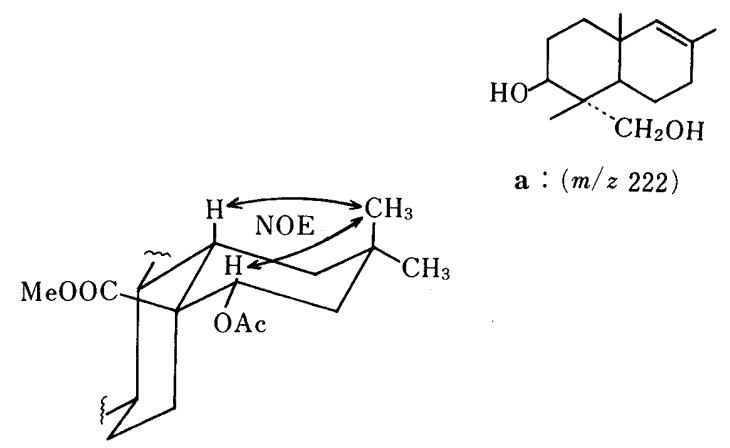

a $:(m / z 222)$

Chart 2

(C) 1989 Pharmaceutical Society of Japan 
TABLE I. ${ }^{13} \mathrm{C}-\mathrm{NMR}$ Chemical Shifts of Kalopanax Saponins in $\mathrm{C}_{5} \mathrm{D}_{5} \mathrm{~N}$

\begin{tabular}{|c|c|c|c|c|c|c|c|c|c|c|}
\hline & \multicolumn{6}{|c|}{ Aglycone moieties } & & \multicolumn{3}{|c|}{ Sugar moieties } \\
\hline & 9 & $11^{a)}$ & 6 & 7 & $\mathbf{8}$ & $10^{7)}$ & & 6 & 7 & 8 \\
\hline & & & & & & & Ara & & & \\
\hline C-1 & 38.80 & 37.74 & 38.79 & 38.65 & 39.23 & 38.53 & 1 & 106.63 & 104.30 & 104.25 \\
\hline $\mathrm{C}-2$ & 27.97 & 23.40 & 26.10 & 26.22 & 26.37 & 27.40 & 2 & 73.14 & 75.79 & 75.88 \\
\hline $\mathrm{C}-3$ & 73.59 & 74.51 & 81.91 & 81.05 & 81.44 & 73.32 & 3 & 74.68 & 74.67 & 74.32 \\
\hline C-4 & 42.60 & 40.53 & 42.56 & 42.55 & 42.89 & 42.59 & 4 & 69.58 & 69.69 & 69.16 \\
\hline C-5 & 48.64 & 47.61 & 47.61 & 47.67 & 48.01 & 48.48 & 5 & 66.92 & 65.78 & 65.36 \\
\hline C-6 & 18.62 & 17.93 & 18.19 & 18.52 & 18.47 & 18.34 & Rha & & & \\
\hline $\mathrm{C}-7$ & 32.85 & 32.16 & 32.77 & 32.80 & 33.04 & 32.74 & 1 & & 101.67 & 101.52 \\
\hline C-8 & 39.96 & 39.43 & 40.02 & 39.96 & 40.16 & 39.54 & 2 & & 72.52 & 71.94 \\
\hline C-9 & 48.15 & 47.86 & 48.15 & 48.15 & 48.39 & 47.92 & 3 & & 72.38 & 83.10 \\
\hline C- 10 & 37.19 & 36.72 & 36.94 & 36.85 & 37.14 & 37.00 & 4 & & 74.13 & 73.01 \\
\hline C-11 & 23.88 & 22.93 & 23.89 & 23.75 & 23.93 & 23.50 & 5 & & 69.30 & 69.79 \\
\hline C- 12 & 122.82 & 123.27 & 122.88 & 122.77 & 122.62 & 122.23 & 6 & & 18.52 & 18.47 \\
\hline C- 13 & 144.21 & 142.17 & 144.19 & 144.26 & 144.51 & 144.57 & Xyl & & & \\
\hline C- 14 & 42.09 & 41.69 & 42.56 & 42.55 & 42.88 & 41.95 & 1 & & & 107.17 \\
\hline C- -15 & 27.69 & 26.86 & 27.98 & 27.98 & 28.27 & 28.10 & 2 & & & 75.54 \\
\hline$C-16$ & 16.90 & 16.82 & 16.90 & 17.01 & 17.49 & 23.45 & 3 & & & 78.27 \\
\hline C. 17 & 53.08 & 50.99 & 53.10 & 53.08 & 53.17 & 46.21 & 4 & & & 71.16 \\
\hline C- 18 & 43.52 & 42.39 & 43.53 & 43.52 & 43.67 & 41.75 & 5 & & & 67.31 \\
\hline C- 19 & 46.20 & 44.90 & 45.95 & 45.98 & 46.70 & 46.40 & & & & \\
\hline C- 20 & 31.53 & 31.42 & 31.53 & 31.48 & 31.58 & 30.67 & & & & \\
\hline C-21 & 43.23 & 39.10 & 43.28 & 43.52 & 43.77 & 33.96 & & & & \\
\hline C-22 & 71.54 & 72.72 & 71.52 & 71.55 & 71.94 & 32.96 & & & & \\
\hline C. -23 & 67.99 & 65.45 & 64.53 & 64.50 & 64.53 & 67.92 & & & & \\
\hline C- 24 & 13.11 & 13.07 & 13.59 & 13.99 & 14.04 & 12.78 & & & & \\
\hline C-25 & 15.94 & 15.74 & 16.07 & 16.03 & 16.28 & 15.69 & & & & \\
\hline C-26 & 17.50 & 16.75 & 17.44 & 17.45 & 17.79 & 17.23 & & & & \\
\hline$C-27$ & 26.71 & 26.23 & 26.71 & 26.71 & 26.66 & 25.88 & & & & \\
\hline C- -28 & 179.50 & 175.04 & 179.40 & 179.60 & 180.05 & 179.86 & & & & \\
\hline C-29 & 33.39 & 32.88 & 33.38 & 33.39 & 33.53 & 32.96 & & & & \\
\hline C -30 & 25.15 & 24.67 & 25.16 & 25.20 & 25.29 & 23.59 & & & & \\
\hline $\mathrm{OCH}_{3}$ & & 51.94 & & & & & & & & \\
\hline \multirow[t]{3}{*}{$\mathrm{CH}_{3} \mathrm{CO}$} & & 170.94 & & & & & & & & \\
\hline & & 170.69 & & & & & & & & \\
\hline & & 170.13 & & & & & & & & \\
\hline \multirow[t]{3}{*}{$\mathrm{CH}_{3} \mathrm{CO}$} & & 21.21 & & & & & & & & \\
\hline & & 21.01 & & & & & & & & \\
\hline & & 20.90 & & & & & & & & \\
\hline
\end{tabular}

a) Determined in $\mathrm{CDCl}_{3}$.

$3 \mathrm{H}, \mathrm{s}$ ), carbon signals see Table I] and exhibited signals due to the following groups at very similar positions to those observed for hederagenin $(\mathbf{1 0})^{7}$; a carboxyl group (a carbon signal at $\delta 179.5$ ), a trisubstituted double bond [carbon signals at $\delta 122.8$ and 144.2, a proton signal at $\delta 5.51(1 \mathrm{H}, \mathrm{t}-$ like)], a primary alcoholic group [a carbon signal at $\delta 68.0$, proton signals at $\delta 3.75,4.20$ (each $1 \mathrm{H}, \mathrm{d}, J=10.8 \mathrm{~Hz}$ )] and a secondary alcoholic group [a carbon signal at $\delta 73.6$, a proton signal at $\delta 4.25(1 \mathrm{H}$, dd, coupling constant could not be determined due to partial signal overlap)]. A proton signal due to $18-\mathrm{H}$ which is characteristic of olean-12-en-28oic acid type triterpenes ${ }^{7)}$ was observed for 9 at $\delta 3.56(1 \mathrm{H}$, dd, $J=4.4,10.2 \mathrm{~Hz}$ ) and the presence of an additional secondary hydroxyl group was indicated by a carbon signal at $\delta 71.5$ and a proton signal at $\delta 4.58(1 \mathrm{H}, \mathrm{dd}, J=5.9$, $10.8 \mathrm{~Hz}$ ). The ${ }^{1} \mathrm{H}-\mathrm{NMR}$ spectrum (in $\mathrm{CDCl}_{3}$ ) of a methyl ester acetate (11) of 9 showed signals due to six quaternary methyls $[\delta 0.73,0.87,1.09,1.17$ (each $3 \mathrm{H}, \mathrm{s}), 0.99(6 \mathrm{H}, \mathrm{s})]$, three acetoxyl groups $[\delta 2.04,2.06,2.16$ (each $3 \mathrm{H}, \mathrm{s})]$, a carbomethoxy group $[\delta 3.62(3 \mathrm{H}, \mathrm{s})]$, the $18-\mathrm{H}[\delta 2.99(1 \mathrm{H}$, $\mathrm{dd}, J=4.4,10.3 \mathrm{~Hz})]$, a primary acetoxyl group $[\delta 3.73,3.92$ (each $1 \mathrm{H}, \mathrm{d}, J=11.6 \mathrm{~Hz}$ )] and two secondary acetoxyl groups $[\delta 4.82(1 \mathrm{H}, \mathrm{dd}, J=5.1,11.2 \mathrm{~Hz}), 5.22(1 \mathrm{H}, \mathrm{dd}, J=$
7.0, 10.3 Hz)]. The fragment-ions which are characteristic of the retro Diels-Alder cleavage of olean-12-en-28-oic acid derivatives were observed as follows (Chart 2); the positive FAB-MS of 9 showed ions at $m / z 223(\mathrm{a}+\mathrm{H})^{+}$and 265 $(b+\mathrm{H})^{+}$and the electron impact mass spectrum (EI-MS) of a methyl ester (12) of 9 exhibited ions at $m / z 278\left(b^{\prime}\right), 219$ $\left(b^{\prime}-\mathrm{COOCH}_{3}\right)$ and $201\left(219-\mathrm{H}_{2} \mathrm{O}\right)$. These results suggested that 9 is a hydroxyhederagenin with an additional hydroxyl group located in the $\mathrm{D}$ or $\mathrm{E}$ ring.

In the ${ }^{13} \mathrm{C}-\mathrm{NMR}$ (Table I), on going from 10 to 9 , signals due to 17-, 21- and 22-C were displaced downfield by 6.9 , 9.2 and $38.6 \mathrm{ppm}$, respectively and that due to $16-\mathrm{C}$ was significantly shifted upfield by $6.6 \mathrm{ppm}$, while other carbon signals remained at almost unchanged positions. Similar displacement of carbon signals was reported from erythrodiol (olean-12-ene-3 $\beta, 28$-diol) to $22 \alpha$-hydroxyerythrodiol. ${ }^{8)}$ Taking into account the hydroxylation shift rule and the $\gamma$-gauche effect ${ }^{9)}$ as well as the coupling constants of the carbinyl proton signal of 9 (and 11) (vide supra), it follows that the additional secondary hydroxyl group of 9 must be located at $22 \alpha$ (equatorial). Assignment of proton signals due to the 29- and 30-gem-dimethyl groups of 11 was substantiated by ${ }^{1} \mathrm{H}-{ }^{1} \mathrm{H}$ and ${ }^{1} \mathrm{H}-{ }^{13} \mathrm{C}$-correlation spec- 
troscopy (COSY) as well as by the COLOC procedure. Irradiation of a signal at $\delta 1.09\left(3 \mathrm{H}, \mathrm{s}, 30-\mathrm{CH}_{3}\right)^{10)}$ resulted in nuclear Overhauser effect (NOE) at signals due to $18-\mathrm{H}$ $(5.5 \%)$ and $22 \beta-\mathrm{H}(4.4 \%)$, confirming the location of the secondary hydroxyl group at $22 \alpha$. Based on these results, 9 can be formulated as $22 \alpha$-hydroxyhederagenin.

The positive FAB-MS of 6 showed ions at $m / z 643$ $(\mathrm{M}+\mathrm{Na})^{+}, 621(\mathrm{M}+\mathrm{H})^{+}, 489(\mathrm{M}+\mathrm{H}-\mathrm{Ara})^{+}$. On comparison of the ${ }^{13} \mathrm{C}$-N.MR spectrum of 6 with that of 9 (Table I), the signal ascribable to $3-\mathrm{C}$ of the aglycone moiety was displaced downfield by $8.3 \mathrm{ppm}$ and the signal due to 2-C was displaced upfield by $1.9 \mathrm{ppm}$ (glycosylation shift), ${ }^{11-13)}$ while other signals remained almost unshifted. Further, signals due to the sugar moiety of 6 (Table I) appeared at almost the same positions as those of $\alpha$-Larabinopyranosides ${ }^{13)}$ such as $\mathbf{1}^{11}{ }^{1)}$ It follows that $\mathbf{6}$ can be formulated as the 3-O- $\alpha-\mathrm{L}$-arabinopyranoside of 9 , as shown in Chart 1.

A new saponin 7 named kalopanax-saponin Lb, exhibited ions at $m / z 789(\mathrm{M}+\mathrm{Na})^{+}$and $767(\mathrm{M}+\mathrm{H})^{+}$in the positive FAB-MS and on acid hydrolysis, 7 afforded $\mathbf{9}$, arabinose and rhamnose. Comparison of the ${ }^{13} \mathrm{C}$-NMR spectrum of 7 with that of 9 demonstrated the same glycosylation shift around 3-C as observed for 6 (Table I). Carbon signals of 7 at $\delta 104.3$ and 101.7 indicated the presence of two sugar units. The observation of a fragment ion at $m / z 621(\mathrm{M}+\mathrm{H}-\mathrm{Rha})^{+}$in the positive FAB-MS of 7 indicated the presence of a terminal rhamnose unit. Carbon signals due to the sugar moiety of 7 (Table I) appeared at almost the same positions as those of $2-O-\alpha-\mathrm{L}-$ rhamnopyranosyl- $\alpha$-L-arabinopyranosides ${ }^{14)}$ such as $\mathbf{3 .}^{11}$ Based on these results, 7 can be formulated as the 3-O- $\alpha-\mathrm{L}-$ rhamnopyranosyl $(1 \rightarrow 2)$ - $\alpha$-L-arabinopyranoside of 9 .

Another new saponin 8, named kalopanax-saponin Lc, exhibited ions at $m / z 921(\mathrm{M}+\mathrm{Na})^{+}$and $899(\mathrm{M}+\mathrm{H})^{+}$in the positive FAB-MS and afforded $\mathbf{9}$, arabinose, rhamnose and xylose on acid hydrolysis. The glycosylation shift around 3-C as well as three anomeric carbon signals at $\delta$ $107.2,104.3$ and 101.5 in the ${ }^{13} \mathrm{C}$-NMR spectrum of $\mathbf{8}$ (Table I) disclosed that $\mathbf{8}$ is a $3-O$-glycoside of 9 which has three monosaccharide units. In the positive FAB-MS of 8 , ions at $m / z 767[\mathrm{M}+\mathrm{H}-\text { pentose }]^{+}, 621[\mathrm{M}+$ $\mathrm{H}-$ pentose $-\mathrm{Rha}]^{+}$and $489[\mathrm{M}+\mathrm{H}-$ pentose $-\mathrm{Rha}-$ pentose] ${ }^{+}$indicated that the sugar moiety of $\mathbf{8}$ consists of a linear pentose-rhamnose-pentose unit. On partial hydrolysis, 8 afforded 6 and 7 which were identified by comparison of the ${ }^{1} \mathrm{H}$ - and ${ }^{13} \mathrm{C}$-NMR spectra with those of respective authentic samples. Further, carbon signals due to the sugar moiety of $\mathbf{8}$ (Table I) were observed at almost the same positions as those of $4 .{ }^{11}$ From these results, the structure of $\mathbf{8}$ was established as the 3-O- $\beta$-D-xylopyranosyl- $(1 \rightarrow 3)$ - $\alpha$-L-rhamnopyranosyl- $(1 \rightarrow 2)-\alpha$-arabinopyranoside of 9 .

\section{Experimental}

Melting points were measured on a micro hot-stage and are uncorrected Optical rotations were taken on a Union PM-101 automatic digital polarimeter. Infrared (IR) spectra were taken on a Shimadzu FTIR-4200 spectrometer. Nuclear magnetic resonance (NMR) spectra were recorded on a JEOL GX-400 spectrometer using tetramethylsilane (TMS) as an internal standard. MS were taken on a JEOL JMS-SX 102 spectrometer. Preparative HPLC was carried out on a column of TSK-gel ODS-120T $(21.5 \mathrm{~mm}$ i.d. $\times 30 \mathrm{~cm})$ with a Toyo Soda HLC $803 \mathrm{D}$ pump and a Toyo
Soda RI-8 differential refractometer as a detector (flow rate of mobile phase: $6 \mathrm{ml} / \mathrm{min})$. For column chromatography, Kieselgel $60(70-230$ mesh, Merck) was used. All solvent systems for chromatography were homogeneous.

Extraction and Separation of Saponins The air-dried leaves of Kalopanax septemlobus $(1.5 \mathrm{~kg})$, collected in Jilin, China, was extracted with hot $\mathrm{MeOH}$. A suspension of the $\mathrm{MeOH}$ extract $\left(139.5 \mathrm{~g}\right.$ ) in $\mathrm{H}_{2} \mathrm{O}$ was washed with $\mathrm{Et}_{2} \mathrm{O}$ and extracted with AcOEt and then with $1-\mathrm{BuOH}$ saturated with $\mathrm{H}_{2} \mathrm{O}$. The AcOEt layer and $\mathrm{BuOH}$ layer were each concentrated to dryness to give the AcOEt extract $(34 \mathrm{~g})$ and $\mathrm{BuOH}$ extract $(11.4 \mathrm{~g})$, respectively. The AcOEt extract was chromatographed on silica gel first with $\mathrm{CHCl}_{3}-\mathrm{MeOH}(6: 1)$ and then with $\mathrm{CHCl}_{3}-\mathrm{MeOH}-\mathrm{H}_{2} \mathrm{O}$ $(40: 10: 1)$ to give three fractions (frs.), frs. I, II and III in order of elution, and each of these was separated and purified by HPLC: fr. I (mobile phase $85 \% \mathrm{MeOH}$ ) gave 1 (yield from dried leaves: $0.008 \%$ ) and $\mathbf{2}(0.01 \%)$; fr. II (mobile phase $77 \% \mathrm{MeOH}$ ) afforded $3(0.21 \%)$ and $6(0.006 \%)$; fr. III (mobile phase $75 \% \mathrm{MeOH}$ ) gave $4(0.01 \%), 7(0.002 \%)$ and $8(0.004 \%)$. The $\mathrm{BuOH}$ extract was chromatographed on silica gel with $\mathrm{CHCl}_{3-}$ $\mathrm{MeOH}-\mathrm{H}_{2} \mathrm{O}(30: 10: 1$ and $70: 30: 5$, successively) to give frs. IV and $\mathrm{V}$, the latter was purified by HPLC with $60 \% \mathrm{MeOH}$ to give 5 (yield, $0.05 \%$ ).

1: Colorless needles $(\mathrm{MeOH}), \mathrm{mp} 228-230^{\circ} \mathrm{C}(\mathrm{dec}),.[\alpha]_{\mathrm{D}}^{20}+48.0^{\circ}(c=$ $0.60, \mathrm{MeOH})$.

2: A white powder, $[\alpha]_{\mathrm{D}}^{20}+11.3^{\circ}(c=0.52, \mathrm{MeOH})$.

3: Colorless needles $(\mathrm{MeOH}), \mathrm{mp} 250-251^{\circ} \mathrm{C},[\alpha]_{\mathrm{D}}^{20}+16.8^{\circ}(c=0.50$, $\mathrm{MeOH})$.

4: A white powder, $[\alpha]_{\mathrm{D}}^{20}+9.6^{\circ}(c=0.46, \mathrm{MeOH})$.

5: A white powder, $[\alpha]_{\mathrm{D}}^{20}-8.3^{\circ}(c=0.80, \mathrm{MeOH})$.

6: A white powder, $[\alpha]_{\mathrm{D}}^{20}+40.4 \quad(c=0.42, \mathrm{MeOH})$. Anal. Calcd for $\mathrm{C}_{35} \mathrm{H}_{56} \mathrm{O}_{9} \cdot \mathrm{H}_{2} \mathrm{O}$ : C, 65.80; H, 9.15. Found: C, 65.75; H, 9.12. ${ }^{1} \mathrm{H}-\mathrm{NMR}$ $\left(\mathrm{C}_{5} \mathrm{D}_{5} \mathrm{~N}\right) \delta: 0.93,0.94,1.00,1.07,1.12,1.29($ each $3 \mathrm{H}, \mathrm{s}), 5.49(1 \mathrm{H}, \mathrm{t}$-like, $12-\mathrm{H}), 4.99(1 \mathrm{H}, \mathrm{d}, J=7.0 \mathrm{~Hz}$, anomeric $\mathrm{H})$.

7: A white powder, $[\alpha]_{\mathrm{D}}^{20}+49.3^{\circ}(c=0.55, \mathrm{MeOH})$. Anal. Calcd for $\mathrm{C}_{41} \mathrm{H}_{66} \mathrm{O}_{13} \cdot 2 \mathrm{H}_{2} \mathrm{O}: \mathrm{C}, 61.32 ; \mathrm{H}, 8.79$. Found: $\mathrm{C}, 61.42 ; \mathrm{H}, 8.64 .{ }^{1} \mathrm{H}-\mathrm{NMR}$ (in $\mathrm{C}_{5} \mathrm{D}_{5} \mathrm{~N}$ ) $\delta: 0.94,0.99,1.12,1.28($ each $3 \mathrm{H}, \mathrm{s}), 1.07(6 \mathrm{H}, \mathrm{s}), 1.64(3 \mathrm{H}, \mathrm{d}$, $J=6.0 \mathrm{~Hz}, \mathrm{CH}_{3}$ of Rha), $5.16(1 \mathrm{H}, \mathrm{d}, J=7.0 \mathrm{~Hz}$, anomeric $\mathrm{H}$ of Ara), 6.27 $(1 \mathrm{H}, \mathrm{s}$, anomeric $\mathrm{H}$ of Rha), $5.48(1 \mathrm{H}, \mathrm{t}$-like, $12-\mathrm{H})$.

8: A white powder, $[\alpha]_{\mathrm{D}}^{20}+45.6^{\circ}(c=0.40, \mathrm{MeOH})$. Anal. Calcd for $\mathrm{C}_{46} \mathrm{H}_{74} \mathrm{O}_{17} \cdot 2 \mathrm{H}_{2} \mathrm{O}: \mathrm{C}, 59.08 ; \mathrm{H}, 8.41$. Found: $\mathrm{C}, 59.49 ; \mathrm{H}, 8.69 .{ }^{1} \mathrm{H}-\mathrm{NMR}$ $\left(\mathrm{C}_{5} \mathrm{D}_{5} \mathrm{~N}\right) \delta: 0.92,1.03,1.06,1.27($ each $3 \mathrm{H}, \mathrm{s}), 0.97(6 \mathrm{H}, \mathrm{s}), 1.66(3 \mathrm{H}, \mathrm{d}, J=$ $6.0 \mathrm{~Hz}, \mathrm{CH}_{3}$ of Rha), $5.01,5.12$ (each $1 \mathrm{H}, \mathrm{d}, J=7.0 \mathrm{~Hz}$, anomeric $\mathrm{H}$ of Ara and $\mathrm{Xyl}), 5.98(1 \mathrm{H}, \mathrm{s}$, anomeric $\mathrm{H}$ of Rha), $5.38(1 \mathrm{H}, \mathrm{t}$-like, $12-\mathrm{H})$.

Acid Hydrolysis of 6, 7 and 8 On heating with $1.5 \%$ aqueous $\mathrm{H}_{2} \mathrm{SO}_{4}$ for $24 \mathrm{~h}$ at $70^{\circ} \mathrm{C}$ followed by work-up in the usual way, 6 afforded 9 and arabinose; 7 afforded arabinose, rhamnose and $9 ; \mathbf{8}$ afforded arabinose, rhamnose, xylose and $\mathbf{9}$. Identification of the resulting monosaccharides was carried out as described in the previous paper. ${ }^{15)}$

9: A white powder, $[\alpha]_{\mathrm{D}}^{20}+67.3^{\circ}(c=0.32$, EtOH $)$. Anal. Calcd for $\mathrm{C}_{30} \mathrm{H}_{48} \mathrm{O}_{5} \cdot 2 \mathrm{H}_{2} \mathrm{O}: \mathrm{C}, 68.67 ; \mathrm{H}, 9.99$. Found: $\mathrm{C}, 68.70 ; \mathrm{H}, 9.77$. IR (Nujol) $\mathrm{cm}^{-1}: 3360(\mathrm{OH}), 1696(\mathrm{COOH})$.

Methyl Ester Acetate (11) of 9 The aglycone $9(20 \mathrm{mg})$ was treated with $\mathrm{CH}_{2} \mathrm{~N}_{2}$ in $\mathrm{MeOH}-\mathrm{Et}_{2} \mathrm{O}$ and the product was purified by column chromatography on silica gel [solvent: $\mathrm{CHCl}_{3}-\mathrm{MeOH}(10: 1)$ ] to give a methyl ester (12) as a white powder, which was acetylated by heating with anhydrous $\left(\mathrm{CH}_{3} \mathrm{CO}\right)_{2} \mathrm{O}(1.5 \mathrm{ml})$ and $\mathrm{C}_{5} \mathrm{H}_{5} \mathrm{~N}(1.5 \mathrm{ml})$ in a sealed tube at $80^{\circ} \mathrm{C}$ for $2-$ $3 \mathrm{~h}$. The reaction mixture was concentrated to dryness by blowing $\mathrm{N}_{2}$ gas over it at room temperature and then purified by column chromatography on silica gel [solvent: benzene-acetone $(8: 1)$ ] to give $\mathbf{1 1}(15 \mathrm{mg})$ as a white powder. Positive FAB-MS $(\mathrm{M}+\mathrm{H})^{+}$Calcd for $\mathrm{C}_{37} \mathrm{H}_{56} \mathrm{O}_{8}+\mathrm{H}: 629.4053$; Found: 629.4027.

Partial Hydrolysis of 8 A solution of $8(45 \mathrm{mg})$ in aqueous $1.5 \% \mathrm{H}_{2} \mathrm{SO}_{4}$ $(15 \mathrm{ml})$ was heated at $70^{\circ} \mathrm{C}$ for $8 \mathrm{~h}$. The reaction mixture was diluted with $\mathrm{H}_{2} \mathrm{O}$ and then extracted with $1-\mathrm{BuOH}$ saturated with $\mathrm{H}_{2} \mathrm{O}$. The $\mathrm{BuOH}$ layer was concentrated to dryness. The residue was chromatographed on silica gel with $\mathrm{CHCl}_{3}-\mathrm{MeOH}(4: 1)$ to give $6(10 \mathrm{mg})$ and $7(12 \mathrm{mg})$, identification of which was achieved by comparison of the ${ }^{1} \mathrm{H}-$ and ${ }^{13} \mathrm{C}$ NMR spectra with those of respective authentic samples.

Acknowledgements This Japan-China joint study was supported by the Research Fellowship Program (long term) of the Japan Society for Promotion of Science to C.-J. Shao in 1989.

\section{References and Notes}

1) C.-J. Shao, R. Kasai, J.-D. Xu, and O. Tanaka, Chem. Pharm. Bull., 37, 311 (1989).

2) Kalopanax-saponin $\mathrm{E}$ in the previous report ${ }^{1)}$ is identical with 
spinasaponin A which has already been isolated from Spinacia oleracea not as a free form, but as a methyl ester [R. Tschesche, H. Rehkaemper, and G. Wulff, Justus Liebigs. Ann. Chem., 726, 125 (1969)].

3) M. Fujita, H. Itokawa, and Y. Kumekawa, Yakugaku Zasshi, 94, 194 (1974); M. Tanemura and K. Takamura, ibid., 95, 10 (1975).

4) G. M. Frolova, Yu. S. Ovadov, and N. I. Suprunov, Khim. Prir. Soedin., 7, 614, 618 (1971); C.-J. Shao, R. Kasai, J.-D. Xu, and O. Tanaka, Chem. Pharm. Bull., 36, 601 (1988).

5) A. Ya. Khorlin, A. G. Ven'yaminova, and N. K. Kochetkov, Dokl. Akad, Nauk. SSSR Ser. Khim., 1966, 1588 (1966)

6) R. Higuchi and T. Kawasaki, Chem. Pharm. Bull., 24, 1021 (1976); R. Encarnacion, L. Kenne, G. Samuelsson, and F. Sandberg, Phytochemistry, 20, 1939 (1981).

7) A. Inada, M. Yamada, H. Murata, M. Kobayashi, H. Toya, Y.
Kato, and T. Nakanishi, Chem. Pharm. Bull., 36, 4269 (1988).

8) K. Tori, S. Seo, A. Shimaoka, and Y. Tomita, Tetrahedron Lett., 48, 4227 (1974).

9) H. Beierbeck and J. K. Sanders, Can. J. Chem., 54, 2985 (1976).

10) H. Kojima and H. Ogura, Phytochemistry, 28, 1703 (1989).

11) R. Kasai, M. Suzuo, J. Asakawa, and O. Tanaka, Tetrahedron Lett., 1977, 175.

12) R. Kasai, M. Okihara, J. Asakawa, K. Mizutani, and O. Tanaka, Tetrahedron, 35, 1427 (1979).

13) K. Mizutani, R. Kasai, and O. Tanaka, Carbohydr. Res., 87, 19 (1980).

14) K. Mizutani, A. Hayashi, R. Kasai, O. Tanaka, N. Yoshida, and T. Nakajima, Carbohydr. Res., 126, 177 (1984).

15) K. Mizutani, K. Ohtani, J.-X. Wei, R. Kasai, and O. Tanaka, Planta Medica, 1984, 327. 